\title{
Subordinate Job Level, Minority Status, and Participation
}

\author{
Dr. Mohammad Shehada \\ Al Isra University
}

\begin{abstract}
In this study, we tested the hypothesis that willingness to use participative approaches is higher when subordinates are lower in job status or from minority group*. To conduct this test, we focused on a decision exercise administered to 60 undergraduate seniors in King Faisl Business School (Saudi Arabia). Subjects evaluated the extent to which participative decision - making strategies were appropriate for work groups of varying job levels and minority status.Results indicated that low - level subordinates and minority groups are more participative than the high-level subordinates.
\end{abstract}

Key Words: Subordinate Job Level, Minority, Participation, Human Relations, Approach.

\section{Introduction}

The role of "Participation" by individuals or groups in the Arab Culture in general and in organizations specifically has been treated by many writers. Its implications for political theory as well as for a theory of Human Relations in formal organizations are numerous. However, in spite of this academic and extra academic interest, a clear - cut, operational definition of the concept, or a precise set of Hypotheses regarding its dynamics, to the best of our knowledge, has not been developed.A review of the literature shows that three major approaches have been taken in dealing with "Participation":

\section{The Experiential Approach}

This approach is exemplified by writers who in the course of their work in enterprise have obtained a "feel" for the role of participation in decision - making process and have put down their experiences in article or book (Cary, 1942). Although writings such as these provide a set of insights and hunches, very little attempts have been made in terms of verification.Most of the formulations are often derived from single sets of observations in a single or in a few enterprises generally made in an uncontrollable fashion. The experiential approach, operating outside the bounds of scientific method, nonetheless, *(In the US minority groups are Blacks, Hispanics, and other minorities. In Saudi Arabia citizens and non-citizens) adds to the scientific knowledge indirectly by providing the raw material from which hypotheses may be molded. The precise structure of these hypotheses is not stated neatly by the experiential writers, but rather remains to be formulated.

\section{The Conceptual (No Experimental Approach)}

This approach characterizes the writings of academicians with strong theoretical backgrounds. Most of their writings deal with "Conditions," "functions," and other abstractions, generally of a socio - psychological nature that try to explain the dynamics of participation. The Conceptual approach at its best is only the process of theory or hypotheses formulation. However, it lays the groundwork for actual testing and experimental work, but much of this type of technical literature available on participation is not clear enough in terms of its conceptual definition.

\section{The Experimental Approach}

This approach is found in the writings of authors who wanted to apply experimental techniques either to specially construct social situations involving participation, or in natural setting in which participational activities prevail. With adequate controls, this approach is without doubt the most useful. Ideally, it indicates what will happen under specific sets of conditions and with what degree of probability.Regrettably, up to now work on the dynamics of participation in decision making has been sporadic (Jago, 1973).

\section{Definition Of Participation}

For the purpose of clarity, it is essential in dealing with participation to define the meaning which is to be attached to the concept. One must specify both who participators are, and in what they are participating. Too often, in the available literature on the subject, readers are left to determine these matters for themselves since no explicit statements, bearing on them, are made by the writers.As already indicated, this paper is primarily concerned with participation as a managerial device. Attention is therefore focused on the subordinates of managers in organizations as the participators. It should be noted that these subordinates may either be non managers or managers (Bartolke, 1982). If they are managers, they are subordinates of superior managers, and 
they also have subordinates responsible to them. In our case, they are subordinates to managers. What then is the meaning of participation, and with what type of participation by subordinates are we concerned? An individual participates in something when he takes part or shares in that thing. Since taking a part or sharing is always involved, participation takes place in a social context (Rosen, 1977). Managerial subordinates in formal organizations are responsible to their superiors for the performance of designated tasks. In such performance, they are participating in the production of the goods or services of the organization.They also participate (Share), through the receipt of wages or salaries in the distribution of the total revenue received by the enterprise. These types of participation are common to all organizations. But there is another type of participation which is much less frequently encountered, although its use as a managerial device has, in recent years grown in importance.This type involves participation by subordinates with their managers in the managerial decision - making process (Tannenbaum, 1974).Decisions are made by managers in order to organize, direct, or control responsible subordinates to the end that all service contributions by coordinates in the attainment of the goals of the organizations (Nightingales, 1979). Since managers are those who accomplish results through subordinates, the subordinates are always directly and intimately affected by managerial decisions and, therefore, may have a considerable interest in them. Due to this possible interest, subordinates may have a strong desire, particularly in a country with hybrid population, like the United Arab Emirates (UAE), to participate in the determination of matters affecting them. It is of importance to consider the form which such participation might take.Decision - making involves a conscious choice of one behavior alternative from among a group of two or more alternatives (William, 1969). There are three steps involved in the decision - making process:

$\underline{\text { First, }}$ an individual must become aware of as many as possible of these behavior alternatives which are relevant to the decision to be made.

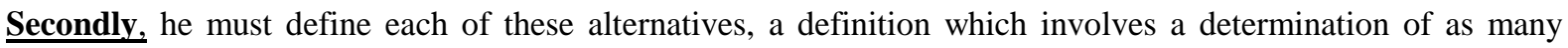
possible of the consequences related to each of the alternatives being considered.

Thirdly, the individual must make a choice between the alternatives and make a decision.In some enterprises, managerial subordinates can participate in the first two steps of decision - making process. They cannot participate in third step. The actual choice between relevant alternatives must be made or accepted by the manager who is responsible to his superior for the decision. However, subordinates can provide and discuss with their managers' information with respect both to relevant alternatives and to the consequences associated with specific alternatives. In this manner, they are participating in the managerial decision - making process. The participation, with which this paper is concerned, involves interaction solely between a subordinate and his manager (Dickson, 1980). What then is the meaning of participation, and with what type of participation by subordinates are we concerned?

\section{The Psychological Conditions Of Effective Participation}

All managers of an enterprise are faced with the problem of evolving service contributions from their subordinates at a high level of quality and intensity. These service contributions are necessary if the formal goals of the enterprise are to be attained. What induces Subordinates to contribute their services? In other words, what motivates them? A motivated individual is one who is striving to achieve a goal; his activity is goaloriented (Willard, 1948). Motivation has been described as potential motion towards a goal. Whether or not the goal is reached depends upon the strength of the force in the direction of the goal, also upon all other forces (including driving and restraining) in a given situation. For example, a person may be motivated to produce 200 units of an item per day, but refraining forces such as machine failure, or a disagreement with the foreman may led him to attain an output of, say 150 unitsIn an organization, the goals towards which individuals strive may be of two kinds. They may be formal goals of the organization or they may be other goals which are complementary to the formal goals. The latter is the typical case. Individuals may strive for monetary reward, prestige, power, security, and like; or they may strive for certain psychological gratifications through the very act of doing the job--that is they work because they like their work. The primary reason why they contribute their services is to attain these later goals. In attaining these desired goals, they make possible the attainment of the formal goals of the enterprise. In this sense, the desired goals and the formal goals are complementary (kolaja, 1982). In the former case, the goals desired by the individual and the goals of the agency are the same. The individual contributes his services primarily because such contribution makes possible the attainment of the formal goals of the agency which coincide with his own personal goals. To the extent that this coincidence of goals exists, the necessity for managers to provide complementary goals is lessened, and the related costs are reduced. It has been suggested that participation tends to bring about a coincidence of formal and personal goals (Barnard, 1977). It may be that through participation, the subordinate who formerly was moved to contribute his 
services because he needed, for example, security and financial rewards now comes to be moved additionally because he realizes that the success of the organization will in turn enhance his own ability to satisfy his needs Whether one sees participation as involving separate subordinates with their superiors or subordinates-ingroups with their superiors, in the final analysis we must realize that the subordinate is a human being with his own personality. That is whether or not participation will bring about the restructuring of his personal goals to incorporate the formal goals depend upon certain psychological conditions some of which are discussed below. (1) The subordinate must be capable of becoming psychologically involved in the participation activities. He must possess some minimum amount of intelligence so that he may grasp the meaning and implications of the thing being considered. He must also be in touch with reality (Dickson, 1982).(2) The subordinate must favor participational activity. In other words, a person who believes the "boss knows best" and that the decisionmaking process is none of his business is not likely to become strongly motivated if given an opportunity to participate. It is apparent that for personality types shaped by authoritarian system opportunities for subordinate participation may be seen as signs of weakness and leadership incompetence and on that basis, may be rejected. (3) The subordinate must also see the relevance of his personal life pattern of the thing being considered. If he realizes that through participation he may affect the course of his future in a positive fashion, he will become motivated. (4) The subordinate must be able to express himself to his own satisfaction with respect to what is being considered. He must be psychologically able to communicate and he must feel that he is making some sort of contribution. Of course, if he does not communicate, he is not participating. If he does not feel that he is contributing, he may be frustrated instead of motivated. This presupposes that he has the required knowledge for participation. Participation may fail if it involves considering matters that are quite outside the scope of knowledge and experience of the participators (Schioleiger, Jago, 1982). All of the above conditions must be satisfied to some extent. It is also apparent that individual differences are highly important in considering the effectiveness of participation as a motivational device; however, the amount of "participation opportunities" made possible by managers is a variable quantity. As a result, it is necessary to inquire what the limits of opportunities to participate should in terms of maximum results. Experience has shown that when some subordinates are given too many opportunities for participation, they may find themselves unable to assimilate effectively the range of "thinking opportunities" with which they are faced (Marshall, 1976).On the other hand, if they are given little or no opportunity to take part in decision- making process they will not be motivated by participational activity. According to William T. Greenwood (1969), for each individual an amount of participational opportunities between these two extremes will result in a maximum amount of motivation. A hypothesis stemming from this formulation is that for effective operation of participation as a motivational device in a group situation, the members of the group must respond similarly to given amounts of participation, because any wide divergences of response may result in social tensions and lack of teamwork within the group As a matter of fact, many factors act together to motivate an individual. Therefore, the usefulness of the above conceptualization depends upon the possibility of breaking down the total of motivational forces into the owing to other factors. Whether or not the increment of motivation due to participation is worthwhile depends to a great extent on the level of motivation that existed prior to the introduction of the device of participation. If motivation has been strong all along, then the effect of participation may not be very great. Subordinate Participation: What is the Right Level? Managers who are unable to identify the appropriate level at which participation should take place may encounter a range of problems. They may establish participation at too low a level and consequently fail to take full advantage of the relevant resources (Hellriegel, 1974). Then, participation would produce inadequate outcomes. On the other hand, if participation is established at too high a level, subordinates may be participating less for participating and just for participation's sake. Also, when managers fail to indicate what they want or expect of the participating employees, nothing of substance can be achieved. Furthermore, if participation is encouraged without a clear-cut purpose, participation may create more problems than it solves. There had been numerous instances where participants don't Know how they should participate, and what the expected products from their participation are (Vroom, Yetton,1 973). Such subordinates are usually unresponsive and unproductive. This will definitely frustrate any manager who wants to use participation as a motivational factor. The managers are not alone in this type of predicament; subordinates too are bound to be frustrated when they eventually discover that their contributions are not used in the way they expected. Although the benefits of subordinate participation in decision-making process is said to be numerous, participation will not produce the desired results if it fails to occur at the appropriate level in the organizational hierarchy. As result, this section of the paper will be devoted to the question of hierarchical level and participation. Among the questions to be answered are: Is participation more appropriate at a certain hierarchical level of the organization than the others? If yes, at what level should subordinate participation be encouraged? By using an empirical study, attempt would be made here to find solutions to these questions. Previous research on level and participation report that those who have high level jobs exhibit greater reliance on subordinates and therefore afford subordinates greater participation in decision making. Many research efforts have specified the nature and cause of the correlation between level and participation. 


\section{Hypotheses}

Ha: Low level subordinates and minority groups are more participative than the high-level subordinates.Ho: Low level subordinates and minority groups are less participative than the high-level subordinates If the hypotheses is supported in this study this means that future managers (Undergraduate Business Senior Students) will be willing to allow and encourage the participation of subordinates.

\section{Method}

The subjects were 76 male and 56 female undergraduate business senior students attending King Faisal University. Experimental materials were embedded in a decision-making exercise. Participants were asked to assume the role of manager for a manufacturer and to respond to a number of incidents (decision problems) requiring policy development or: change in various departments. Four of the incidents were written in two versions so as to manipulate the independent variables. We divided the classes into two sections. One section of the class received one version of the questionnaire and the other section received the other version. Both sections were not aware that other versions existed, and also not aware that job level is a factor. Because of the large number of students and time limitations, we picked up only 60 students (35 male and 25 females) randomly, out of 132 .

The decision problems and the experimental variables are:

1) Laborers versus technicians: Here employees in the shipping department are requesting to determine their own work schedules. They, also, would guarantee that the department had sufficient manpower on hand during rush periods. In one version of the questionnaire, employees were described as "manual laborers" and in the other version, as "technicians"

2) Production workers versus junior executives. The level of employee participation in the planning of a new cafeteria and lounge is to be determined by participants. Emplolees were described as "production workers" in one version and "junior executives" in the other.

3) Janitors versus draftsmen. This problem involves frequent inventory shortages leading to excessive "down time" among either a janitorial staff or a drafting staff. On one version, participants were required to decide on the extent of janitors' participation and on the other version, on the extent of draftsmen.

4) Minority versus non-minority clerical staff. Here participants were asked to recommend the extent to which the clerical staff should participate in the development of an appearance policy. And on the other version, participants were asked on the extent to which non-minority clerical staff should participate.

The degree to which participants would employ to determine a participative decision strategy include the following alternatives:

a) Definitely would not allow employees to participate.

b) Probably would not allow employees to participate.

c) Probably would allow employees to participate.

d)Definitely would allow employees to participate.

The hypothesis is strongly supported in incident 1 and 2. Subjects support a participative decision strategy for use with "Manual Laborers" compared to "Technicians", in work scheduling. According to statistics, (66. 7\%) respondents (future managers) are more willing to let their low-job level subordinates "Manual Laborers" participate in the decision-making process, rather than their high. - job level subordinates "Technicians" (63.3\%). Similarly, other participants are willing to endorse subordinate participation for the design of a new cafeteria when subordinates were described as "Production Workers" (76.7\%) rather than "Junior Executives" (70\%).In incident 3, respondents were willing to endorse participative decision making with respect to managing an open budget for "Janitors" (23.3\%) rather than "Draftsmen" $(20 \%)$. Incident 4, states that "Minority Clerical Staff" is recommended for employee participation in deciding on an appearance policy $(86.7 \%)$ rather than non- minority staff $(73.3 \%)$.These findings are significant at $<.05$.

\section{Discussion}

All these findings support the hypothesis that the willingness to use participative approaches is higher when subordinates are lower in job status or from minority groups. Generalization in this paper must be made with caution because our findings are based on reactions of undergraduate senior business students. These findings oppose Maier's (1963) and Leavitt's (1972) assertions that managers resist participative methods because they fear that subordinates will make low quality decisions. It has been a widely-shared belief that participation is more useful at the high levels of the organizational Maier (1963) and Leavitt (1972). However, this analysis based on our findings rejected the previous hypotheses. The presence of hierarchical level effect points to a different direction. We should be reminded that there are two theories of participation: human relations theory, and human resources theory. A manager who sees participation as a tool for improving the morale and satisfaction of subordinates in order to reduce their resistance to formal authority reflects the human 
relations theory of participation. On the other hand, the manager who sees participation as a means to improve the quality of decision making and overall performance of his group reflects the human resource theory of participation. The type of approach a manager gives to participation depends upon which of the above schools of thought he belongs to.According to Vroom and Yetton, managers who conform to the human resources theory would restrict subordinate participation to those situations where Subordinate experience could be useful in resolving the problem of decisions. Managers adopting the human relations approach could consult subordinates on problems having quality requirements. However, they are not expected to limit subordinate participation to these situations. They would still encourage participation in problems without quality requirement (Nightingale, 1981). Subordinate participation at the lower level of the organizational hierarchy has economic advantage. People at the higher level earn high salaries, as a result, it would be more expensive (greater opportunity costs) for the organization to get them involved in time-consuming participation processes. The decision by most of the respondents not to allow much participation in those high-level situations is therefore, rational. At low levels participation incurs less cost. As a result, it needs only minimum benefits to justify it (Kumar, 1980). Another probable reason why most of the managers favored subordinate participation at the low level is the problems of low morale and job dissatisfaction which permeates the lower levels of every organization. People are not motivated at this level because of the routine nature of the jobs which make them very boring (Harzberg, Mausner, Peterson, and Capwell 1957).

\section{Conclusion}

Although the benefits of subordinate participation in decision making are numerous, it should be used with great caution. For instance, low hierarchical level participation in obviously trivial or routine matters may improve subordinate morale, reduce resistance, to formal authority and decrease interdepartmental friction. Alternatively, such, participation may be seen by subordinates as manipulative, exploitative and even immoral (Smirchich, Chesser, 1981). If it is thus perceived, it may not yield the intended results. Over time, such participation may create problems for the manager and strain the relationship with subordinates. There are some interesting findings from this study, it specifies when and with whom managers are likely to share decisionmaking reasonability. However, the results of this investigation are far from being conclusive, especially when similar studies in the past produced completely different results. It is also not clear whether or not certain contingencies have influenced the outcome.

\section{Recommendations And Future Research}

In light of these further empirical studies it might be required to authenticate these findings and conduct a follow up for those Undergraduate Senior Business Students who are becoming managers in the future. Another important note about the use of participation as a means of motivating subordinates is that little is known in terms of its long run effects. Attention has not been paid to this important aspect of participatory management. However, in spite of the absence of empirical studies, it is commonly believed that, after an initial spurt, beneficial effects will be attained, which finally will decline unless other managerial devices are skillfully employed. It is hoped that more studies would be conducted on this subject in the near future.

\section{References}

[1] Alison Wood Brooks, Hengchen Dai, Maurice E. Schweitzer, (2014), “ I'm Sorry About the Rain! Superfluous Apologies Demonstrate Empathic Concern and Increase Trust”, Social Psychological and Personality Science, 5:4, 467-474.

[2] Arthur G. Jago (1981), "An Assessment of the Deemed Appropriateness of Participative Decision Making for High and Low Hierarchical Levels", Human Relations, Vol. 34, No.5, 380-390.

[3] Bartolke, k. (1982), "Workers' Participation and the Distribution of Control as Perceived by Member of ten German Companies", Administrative Science Quarterly, 271, 381-392.

[4] Dennis, M. D. \& Susan, E. (2003). "Perceptions of Supervisory, Middle Managerial, and Top Managerial trust: The Role of Job Satisfaction in Organizational Leadership" Pope North Carolina State University Raleigh,' NC. American Political Science Association, Philadelphia, PA.

[5] D. Frost, "Survey Finds Many Workers Mistrust Bosses," San Francisco Chronicle, January 3, 2007, www.SFGate.com

[6] Dickson, J.W., (1980) "Perceptions of the Direct and Indirect Participation in British Companies", Journal of Applied Psychology, 65, 226-232.

[7] Dickson, J.W., (1982) “Top Managers’ Beliefs and Rationales for Participation”, Human Relations, 35 , 210-221.

[8] D. Koeppel, “A Tough Transition: Friend to Supervisor,” The New York Times, March 16, 2003, p. BU12. 
[9] Edward C. Tomlinson, Roy J. Lewicki, Steven R. Ash, (2014), "Disentangling the Moral Integrity Construct", Group \& Organization Management, 39:6, 720-743.

[10] Foster, S. T. (2007), Managing Quality: Integrating the Supply Chain, New Jersey, Prentice Hall. J. Hempel, and S. Porges, "It Takes a Village-and a Consultant", Business Week, September 6, 2004, Goldy Brown, III., (2015), “ Strong One Lasting One”, Journal of Cases in Educational Leadership, 18:4, 309316.

[11] Jago, A.G., (1977) Hierarchical Level Determinants of Participative Leader Behavior, (unpublished doctoral dissertation, Yale University, 33-43.

[12] Hellriegel, D., and J.W. Slocum, Jr, (1980) "Organizational Climate: Measures, Research and Contingencies", Academy of Management Journal,17, 255-260.

[13] Herzberg, F., Mausner, B., Petreson, R.D., (1957) Job attitudes: Review of Research Opinion, Pittsburgh: Psychological Service of Pittsburgh, 43-67.

[14] Kolaja, J., (1982) "Worldwide Interest in Worker Participation in Management", American Journal of Economics and Sociology, 11-13.

[15] Kumar, U. (1980) "Identity Status and Preference of Managerial Styles", Journal of Social Psychology, 110, 295-296.

[16] Lixin Jiang, Tahira M Probst. (2016) "The Moderating Effect of Trust in Management on Consequences of Job Insecurity", Economic and Industrial Democracy

[17] Marsrall, S., (1976) "Changing Toward Participative Management Approaches", Management Review, 75-82.

[18] Mir Abdolhasan Askari Rankouh, Payam Nikbakhsh Saberi Poor, (2013), "Examine the Relationship between Organizational Culture and Creativity of Lecturers", Universal Journal of Management and Social Sciences Vol. 3, No.8; 24-30

[19] Molden, D. (2007), Managing with the Power of NLP, 2le, Harlow, prentice Hall, NJ.

[20] Nightingale, D. V., (1979) “The Formally Participative Organization”, Industrial Relations, 18, $311-320$

[21] Oshagbemi, T. (2003). "Personal Correlates of Job Satisfaction: Empirical Evidence from UK Universities," International Journal of Social Economics, Vol. 30 No. 12, pp. 1210-32.

[22] Osibanjo Omotayo Adewale, and Adeniji Adenike Anthonia, (2013), "Impact of Organizational Culture on Human Resource Practices: A Study of Selected Nigerian Private Universities", Journal of Competitiveness, Vol. 5, Issue 4, pp. 115-133

[23] Peter J. Dowling, Marion Fisting \& Allen D. Engle, Sir, (2008), International Human Resource Management, Thomas, Learning.

[24] R. D. Arvey, Z. Zhang, and B. J. Avolio, (2007), "Developmental and Genetic Determinants of Leadership Role Occupancy among Women,” Journal of Applied Psychology, pp. 693-706

[25] Rhodes, L. D. \& Hammer, E.Y. (2000). 'The Relation between Job Satisfaction and Personality Similarity in Supervisors and Subordinates,' Psi Chi journal of Undergraduate Research, vol. 1, pp 46-262

[26] Robbins, Stephen, Judge, Timothy (2009), Organizational Behavior, 13ed. Person, Prentice Hall,.ScottLadd, B., Travaglione, A. \& Marshall, V. (2006) "Causal Inferences between Participation in Decision Making, Task Attributes, Work Effort, Rewards, Job Satisfaction and Commitment," Leadership and Organizational Development Journal Vol. 2 No. 5 pp $3999-414$ 